\title{
Zahnmedizinrecht Von A wie Aufklärungsfehler bis Z wie Zahnarzthaftung
}

\section{Authors: Tim Oehler Publisher: Georg Thieme Verlag KG}

Language: German

ISBN: 978-3-13-170941-7

Edition: 1/e

Publish Year: 2013

Pages: 320

Price: $€ 79.99$

Tim Oehler's book entitled Zahnmedizinrecht Von A wie Aufklärungsfehler bis Z wie Zahnarzthaftung (Dentistry Law from Error Solving to the Dentists' Legal Responsibility) addresses dentists and also those who are interested in legal issues connected to the contemporary dentistry current practice.

The reader can benefit from the inductive method which allows him an easy approach to this legal field. At the same time, the book also addresses patients, as it is a genuine information source.

The book describes a series of court decisions and presents a number of standard legal decisions. The court rulings also include quotations from previous court cases. The author also describes various aspects pertaining to his own personal cases.

The content of the book is absolutely unique, as it illustrates legal issues arising in the daily dental practice. The cases selected and presented in detail involve the dentist directly (as plaintiff or defendant) or indirectly.

The reader may compare his own case with the decisions taken by the court in a similar case presented in the book.

The author describes a series of typical legal examples which can occur in a dental practice, as well as the examination and solution to the case, the court ruling and also his criticism with respect to the decision. The book is indeed original as it refers to legal issues which occur in the current dental practice.

The chapters are built around a number of similar cases followed by a standard court ruling.

The reader can become acquainted with the

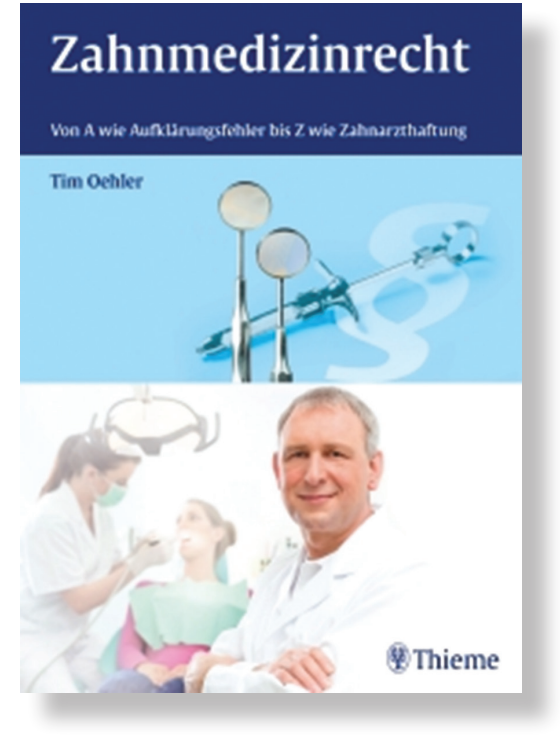

legal provisions and is given the possibility to move on the legal «minefield».

While reading the book, a patient can assess his own case against the backdrop of current case law.

Based on the court rulings pertaining to dental practice, the reader can develop his ability to become aware of the legal framework. "Becoming aware of the legal situation» is also useful for dentists in order to avoid malpractice cases and provide patients with better certainty. An appropriate presentation of standard court rulings facilitates the development of a critical legal thinking in the dental office, while playing a role in the daily monitoring of dental practice.

Tim Oehler's book provides rich, significant and useful information on the legal issues related to the contemporary dental practice, and its translation into English would make it more accessible both to patients and dental practitioners.

Yet, there is one aspect worth mentioning - law interpretation varies with the country, so the situation described for Germany may not be the same in other states. What is important is the overall approach to such legal matters and the fact that a solution can be found in keeping with the legal tradition of each country.

https://doi.org/10.25241/stomaeduj.2016.3(1-2).bookreview.5

Marian-Vladimir Constantinescu,DDS, PhD

ROPOSTURO - Holistic Dental Medicine Institute, Bucharest, Romania

e-mail:dr.vladimir.constantinescu@gmail.com

The Book Review is drafted in the reviwer's sole wording and illustrates his opinions. 